\title{
Title: FK506-binding protein FkIB is involved in biofilm formation through its peptidyl-prolyl isomerase activity
}

\section{Authors and affiliations: Chrysoula Zografou, Maria Dimou, Panagiotis Katinakis}

Laboratory of General and Agricultural Microbiology, Faculty of Crop Science, Agricultural University of Athens, lera Odos 75, 11855 Athens, Greece

\section{Abstract}

FkIB is a member of the FK506-binding proteins (FKBPs), a family that consists of five genes in Escherichia coli. Little is known about the physiological and functional role of FkIB in bacterial movement. In the present study, FkIB knock-out mutant $\Delta f k l B$ presented an increased swarming and swimming motility and biofilm formation phenotype, suggesting that FkIB is a negative regulator of these cellular processes. Complementation with Peptidyl-prolyl isomerase (PPlase)-deficient fklB gene (Y181A) revealed that the defects in biofilm formation were not restored by $Y 181 A$, indicating that PPlase activity of FkIB is modulating biofilm formation in $E$. coli. The mean cell length of $\Delta f k l B$ swarming cells was significantly smaller as compared to the wild-type BW25113. Furthermore, the mean cell length of swarming and swimming wild-type and $\Delta f k l B$ cells overexpressing $f k l B$ or $Y 181 A$ was considerably larger, suggesting that PPlase activity of FkIB plays a role in cell elongation and/or cell division. A multi-copy suppression assay demonstrated that defects in motility and biofilm phenotype were compensated by overexpressing sets of PPlase-encoding genes. Taken together, our data represent the first report demonstrating the involvement of FkIB in cellular functions of $E$. coli.

\section{Introduction}

The previously prevalent view of bacteria development was considered to be the planktonic form of life. That is, unicellular organisms that grow as individual entities. This view has changed as it has been found that bacteria, under given conditions, behave as multicellular groups that grow on nutrient-rich surfaces, secrete a polysaccharide material, through a process called swarming motility. Swarming motility is mainly driven by rotating flagella, and swarming bacteria generally appear to be elongated as a result of cell division suppression [1][2]. In contrast to swarming, swimming describes a mode in which cells move within aqueous environments, not in groups, but independently, by operating their rotating flagella [3]. A comparable type of multicellular behavior is the biofilm formation where bacteria form sessile communities and disperse by secreting proteins and surfactants extracellularly [4]. Biofilms are complex systems and can be composed of multiple species [5]. Environmental conditions and coordinated life cycles can affect or set off heterogeneity and include, among other, expression of genes and proteins, as well as posttranslational protein modifications (PTMs), that could alter environmental sensing and signal transduction [6][7]. Various PTMs such as glycosylation, N-terminal modifications and phosphorylation are few of the 
functional properties of Peptidyl-prolyl cis/trans isomerases (PPlases). PPlases, being ubiquitous among all organisms, are key regulators of numerous highly important biological processes; they accelerate the rate of in vitro protein folding and they have the ability to bind proteins and act as chaperones.

Additionally, PPlases catalyze the folding of newly synthesized protein targets, particularly those that have peptide bonds in the trans conformation. They are also able to alter the structure and conformation of mature proteins thus affecting their intermolecular interactions [8]. In bacteria and other organisms, there are three characterized PPlase subfamilies; the Cyclophilins, the FK506-binding proteins (FKBPs), and the Parvulins. E. coli FKBP family consists of five genes; $f k p A, f k p B, f k l B, s / y D$ and tig, none of which is essential for growth [9]. FKBPs are found to be involved in a diverse series of cellular processes such as cell division [10], stress response regulation and development [11], gene regulation through transcription and translation [12], and most importantly, virulence and pathogenicity [13].

E. coli FkIB (or FKPB22) possesses PPlase activity, exists in solution as a homodimer and shares a significant homology with the protein Mip (macrophage infectivity potentiator) that is identified in a number of human pathogenic bacteria, such as Legionella pneumophila, Neisseria gonorrheae, and Chlamydia trachomatis in the psychrotrophic bacterium Shewanella sp. SIB1 [14] but also in the plant pathogen Xanthomonas campestris [15]. Shewanella SIB1 FKBP22 is composed of two monomers that are connected at their N-termini, bearing a V-shaped structure. Within the monomer, a 40-residue long a-helix separates the $\mathrm{N}$ - and $\mathrm{C}$-terminal domain [16]. An almost identical tertiary structure appears to be assumed by the E. coli FkIB [17]. Data suggest that the probable PPlase binding site of SIB1 FKBP22 for a protein substrate is located at its C-terminal domain. Abrogation of SIB1 FKBP22 PPlase activity did not significantly affect its chaperone function [18].

This paper describes a new approach to investigate the physiological role and assess the PPlase and chaperone function of FkIB through a series of phenotypic methods. We focused on genetic and biochemical approaches to assess the swarming and swimming motility, biofilm and cell length phenotypes in $E$. coli, caused either by the loss of $f k I B$ or by the overexpression of $f k l B$ and of PPlase-deficient $f k l B$ $(Y 181 A)$ gene. We found that deletion of $f k I B$ resulted in an enhancement of motility and biofilm, as well as a decrease of swarming cells' length. Complementation with $f k l B$ gene, in the mutant strain $\triangle F k l B$, suppressed the $f k I B$ deletion motility and biofilm phenotype, while overexpression of $Y 181 A$ suppressed only the motility phenotype. Overexpression of $f k I B$ or $Y 181 \mathrm{~A}$ gene exhibited opposite effects on the mean cell length of swarming and swimming cells. We also used a multi-copy suppression approach to assess if overexpression of other PPlase-encoding genes may suppress the $\Delta f k I B$ strain motility and biofilm phenotypes. 


\section{Results \& Discussion}

\section{PPlase and chaperone activity of FkIB}

Initially, we examined the PPlase activity of FkIB with a standard PPlase assay of isomer-specific proteolysis by chymotrypsin, described by Kofron [19]. Based on the protein alignment of E. coli FkIB (Ec_4207) with the fully characterized human FkpB12 (hfkpB12), we located the FklB's putative active sites. We then constructed an active site mutated form of FkIB, Y181A, which we used in the PPlase assay in comparison to the wild-type FkIB. N-succinyl-Ala-Ala-Pro-Phe-pnitroanilide was used as a substrate known to mimic the internal peptidyl-prolyl moiety of proteins containing proline.

We found that Y181A had no measurable isomerase function, whereas the catalytic efficiency of FkIB was $1.50 \pm 0.0013(\mathrm{Kcat} / \mathrm{Km})$, suggesting that substitution of $\mathrm{Y} 181$ had a significant effect on its activity (Fig. 1A). This result suggests that $\mathrm{Y} 181 \mathrm{~A}$, located on its $\mathrm{C}$-terminal domain, is involved in the catalytic function of the enzyme. Previous findings have demonstrated that the catalytic efficiencies of other mutant forms of FkIB indicate that W157 and F197 are also critically important for the isomerase activity of SIB1 FKBP22 [20].

Next, we sought to determine the chaperone activity of FkIB by measuring its ability to suppress the thermal aggregation of citrate synthase (CS) [21], while also evaluating any effects on it, caused by the induced active site mutation. CS tends to aggregate at high temperatures because of hydrophobic interactions between unfolding intermediates and results in the formation of high molecular weight particles. Proteins with a chaperone function are able to recognize and bind to these unfolding intermediates and therefore keep their concentration low in solution. We observed that wild-type FkIB presents a chaperone function, whereas the inhibition of the CS aggregation from Y181A appears to increase in proportion to its concentration (Fig. 1B).

However, we noticed an increased ability of Y181A to inhibit the formation of CS aggregates, in comparison to the wild-type FkIB. This may be an indication that the loss of FkIB's PPlase activity improves its function as a chaperone.

It has been previously shown that the PPlase and chaperone activity of SIB1 FKBP22 reside in two structurally unrelated domains, but not necessarily functionally independent domains. Mutations at its PPlase active site do not critically affect its chaperone function, an indication that SIB1 FKBP22 does not require PPlase activity for protein folding. However, the authors highlight the importance and requirement of the chaperone domain for the PPlase activity, as a way of enabling the formation of folding intermediates [20]. Several other studies have also indicated that the presence of chaperone activity improves PPlase activity [22] [23]. The substrates are bound to the chaperone site and are subsequently transferred to the PPlase site, where the peptidyl-prolyl bonds of the proteins are being isomerized. Protein molecules, that exited the PPlase site with an incorrect peptide-prolyl bond, are re-attached to the chaperone region and the procedure is repeated [23]. Therefore, it could be assumed that the chaperone activity of FkIB may offset a high PPlase activity and concurrently the loss of PPlase activity might allow structural changes 
that increase the chaperone activity. Elucidating the structural relationship and association of the two functions is very important in order to uncover the role of the PPlase family in major cellular processes.

\section{Role of FkIB in swarming and swimming motility}

The role of FkIB was examined under swarming and swimming conditions, by inoculating the center of swarming (LB-glucose, $0.5 \%$ agar) and swimming plates (LB, 0.3\% agar) with liquid cultures expressing and/or lacking the $f k I B$ gene (Fig. 2). We found that the mutant $\Delta$ FkIB strain formed considerably larger swarming and swimming colonies in comparison to the control strain, BW25113, indicating that the loss of FkIB is responsible for the observed phenotype (Fig. 2A-B). In order to validate that FkIB functions as a swarming and swimming motility repressor we examined the phenotypes of the $\triangle \mathrm{FkIB}$ strain and of the control strain overexpressing the $f k l B$ gene (strain BW25113(FklB)). We found that the $\Delta \mathrm{FklB}(\mathrm{FklB})$ reverted the hyper-swarmer or hyper-swimmer phenotype to wild-type, while BW25113(FkIB) further suppressed the phenotype beyond the wild-type levels (Fig. 2A-D). This observation supports our initial hypothesis that the lack of FkIB was the causative factor of the increased swarming and swimming motility. Growth rates of $\triangle \mathrm{FkIB}$ or BW25113 (FklB) strain liquid cultures were comparable to the control's, suggesting that the increased motility phenotype was not attributed to an increased growth.

Subsequently, we checked the involvement of the PPlase activity of FkIB protein in swarming and swimming motility by following the same conditions. Strain $\triangle \mathrm{FkIB}(\mathrm{Y} 181 \mathrm{~A})$ did not seem to differ from the corresponding strain $\triangle \mathrm{fkIB}(\mathrm{FkIB})$, even in highest IPTG concentrations, as both displayed no motility on swarm or swim plates, suggesting that the PPlase activity of FkIB is not likely to be involved in the mechanism. Overall, we found that the expression of FkIB and its mutant form, $\mathrm{Y} 181 \mathrm{~A}$, is able to restore the wild-type phenotype at all IPTG concentrations (0.1-0.5 mM). This confirms that the presence of FkIB is indispensable for maintaining a normal phenotype, perhaps through pre- and post-translational modifications or indirect target protein interactions that control a wide range of cellular processes, including motility [24] [25]. The negative regulation of swarming and swimming motility in E. coli by certain PPlase family members was previously shown [26][27]. FkpB proteins are found to be involved in bacterial motility, for example, an increase in the transcript levels of $f k I B$ gene was observed in $P$. mirabilis swarming cells [28]. Another example is the Gldl protein of the microorganism F. johnsoniae, a lipoprotein homologous to FKBPs, essential for gliding mobility [29]. Although the structure of almost all FKBP proteins has been extensively studied, our knowledge about their biological role still remains limited. We already know that FKBPs catalyze the refolding of peptides preceding proline at polypeptide chains, as well as that all exhibit some PPlase activity, but there are still several unanswered questions about their physiological role.

\section{FkIB is suppressing $E$. coli's biofilm formation ability}

Swarming motility and biofilm formation relationship seems to be complex and although both conditions share some common constituents, they greatly differ. Specifically, the use of flagella is necessary for 
biofilm initiation, but motility is also required for its initiation, as well as dispersion and release of bacteria [30]. However, it is not clear whether there is an inverse regulation of swarming motility and biofilm formation, as conflicting data have been published. For example, an increased EPS production suppressed swarming motility, but enhanced biofilm formation among laboratory isolates [31]. Biofilm formation, as well as swarming and swimming motility, was suppressed by overexpressing the cyclophilin PpiB. However, this involvement of $\mathrm{PpiB}$ in the biofilm formation phenotype does not involve its prolyl isomerase activity [32]. Biofilm formation was explored for FkIB in order to elucidate the role of its PPlase function in this multicellular behavior, but also to investigate into its relation to swarming. To this means, we initially compared the biofilm formed by the control BW25113 and the mutant strain $\triangle F k I B$ and we noticed that the $\triangle$ FkIB strain was capable of a greatly increased biofilm formation (Fig. 3). We hypothesized that the increased biofilm formation by $\Delta$ FkIB was attributed to the absence of the FkIB protein and in order to clarify this we tested the biofilm formation under the same conditions of the strain $\Delta \mathrm{FkIB}(\mathrm{FkIB})$ as well as the strain BW25113(FkIB). Indeed, we noticed the restoration of the wild-type phenotype, when FkIB was expressed at intermediate IPTG concentrations (0.1-0.25 mM), in the mutant strain $(\triangle \mathrm{FkIB}(\mathrm{FkIB}))$ and in the wild-type strain (BW25113(FklB)). Interestingly, we further detected a biofilm repression phenotype when FkIB was overexpressed (0.5 mM IPTG), either in BW25113(FklB) or in $\triangle F k l B(F k I B)$ strain, suggesting that FkIB bears a key role in biofilm formation (Fig. 3A-B).

Similarly, we tested the strains that overexpress the mutant protein $\mathrm{Y} 181 \mathrm{~A}, \Delta \mathrm{FkIB}(\mathrm{Y} 181 \mathrm{~A})$ and $B W 25113(Y 181 A)$. The results showed that the biofilm of strain $\Delta F k I B(Y 181 A)$, did not differ from the mutant strain $\triangle \mathrm{FkIB}$, even in the presence of high levels of IPTG $(0.25$ and $0.5 \mathrm{mM})$. The overexpression of the mutant Y181A did not cause a restoration of the wild-type phenotype. Based on these results, we can conclude that FkIB's PPlase activity is involved in this multicellular behavior (Fig. 3A).

Additionally, the strain BW25113(Y181A), in the absence or presence of low levels of IPTG $(0.1 \mathrm{mM})$, showed similar biofilm formation ability to the control BW25113. However, we noticed that even though the strain BW25113(Y181A) at 0.25 and $0.5 \mathrm{mM} \mathrm{IPTG,} \mathrm{showed} \mathrm{an} \mathrm{important} \mathrm{decrease} \mathrm{in} \mathrm{biofilm} \mathrm{formation,}$ that decrease was slightly lower than BW25113 (FkIB) ((Fig. 3B). These observations seem to suggest that FkIB has an important role in suppressing the biofilm formation phenotype of $E$. coli and that its PPlase activity is indispensable for this involvement.

\section{PPlase family members can functionally replace FkIB in swarming, swimming and biofilm cells}

Previous research has demonstrated that two members of the PPlase family are functionally linked in yeast cells. It was found that although these proteins do not bind or catalyze the same peptides, they can generate conformational changes to substrates [33]. Another study has showed that a parvulin and a FKBP protein catalyze the cis/trans isomerization of peptide bonds in proteins with great homology [34]. Based on the above studies, we questioned whether the previously observed phenotypes of $\Delta \mathrm{FkIB}$ mutant strain could reverse upon expression of members of the PPlase family. To this end, we separately introduced 
and expressed plasmids that contained each gene belonging to the PPlase family; $f k p A, s / y D, f k p B$, tig, ppiA, ppiB, surA, ppiC and ppiD into the $\triangle \mathrm{FkIB}$ mutant strain and we compared the ability of each one of swarming, swimming and biofilm formation (Fig. 4).

Interestingly, we found that the multiple copies of all gene members of the PPlase family (0.5 mM IPTG), but not the member tig of the FKBP family, could rescue the hyper-swarming phenotype of the $\triangle \mathrm{FkIB}$ mutant (Fig 4A). The hyper-swarmer phenotype of $\triangle$ FkIB was restored to wild-type levels even at single copies of genes $f k p A$, ppiD, and of course fkIB (0 mM IPTG). This observation could be evidential of a functional overlap between FKBPs and parvulins, in swarming bacteria, perhaps hinting at the cis/trans isomerization of some common substrates.

The hyper-swimmer phenotype of $\triangle F k I B$ was rescued upon expression of the majority of PPlases, excluding the cyclophilins ppiA and ppiB. Every member of the FKBP family was able to complement FkIB's function in swimming cells even in single copies (0 mM IPTG). There was a significant increase detected at high expression levels of tig (0.5 mM IPTG), which indicates a unique involvement of the trigger factor protein in swimming motility (Fig. 4B).

Lastly, we checked the biofilm formation phenotype of the $\Delta \mathrm{FkIB}$ could be abrogated by members of the PPlase family. We found that the expression of a great number of PPlases was not able to functionally replace FkIB. The members PpiA, PpiB, FkpB, Tig, PpiC, and PpiD did not rescue the increased biofilm of the mutant strain $\triangle F k I B$, at low levels of expression (0 mM and $0.1 \mathrm{mM} I P T G)$. Wild-type biofilm levels were recovered in the high-copy presence of PpiB, PpiC, and SurA (0.5 mM IPTG) and in the intermediatecopy presence of FkIB and FkpB (0.25 mM IPTG). Interestingly, we identified a biofilm suppression phenotype after expressing high-levels of FKBP encoding genes, $f k p A$, fkpB, slyD, and $f k I B$ (0.5 mM IPTG) (Fig. 4C).

The evidence from the above experiments point towards the idea that members of the PPlase family can compensate for the absence of FkIB, in swarmer, swimmer and biofilm E. coli cells. This functional replacement is even possible at very low copy numbers of PPlases, suggesting that there might be a substrate regulation pathway shared within the PPlase family. The data also indicate that there is a stronger physiological function commonality among members of the FKBP family through the regulation of cellular processes, post-translationally [26].

\section{FkIB expression causes cell morphology alterations}

Swarmer cells are described as elongated and hyperflagellated cells, that are able to migrate towards the edge of a swarming plate or a nutrient-rich surface, away from the initial colony [35] [36] [37]. We have previously examined E. coli cells in a planktonic phase that lack or overexpress the cyclophilin PpiB and found that in both cases the present an impaired cell division [38].

In this study, we examined the cell morphology of the control BW25113 and of the mutant $\Delta \mathrm{FkIB}$, as well as of the strains that overexpress FkIB; BW25113(FkIB), BW25113(Y181A), $\Delta \mathrm{FkIB}(\mathrm{FkIB})$ and 
$\triangle \mathrm{FkIB}(\mathrm{Y} 181 \mathrm{~A})$, during swarming and swimming motility. The expression of plasmids that carried the $f k l B$ gene and its mutant, Y181A, was performed in the presence of $0.1,0.25$, and $0.5 \mathrm{mM}$ IPTG. We microscopically observed all the above strains after Gram staining and after DAPI staining, using an optical and a fluorescence microscope, respectively, showing the expression of FkIB and Y181A at 0.25 mM IPTG (Fig. 5, 6).

In swarming cells, we observed that the absence of the $f k l B$ gene (strain $\triangle \mathrm{FkIB}$ ) did not result in a differentiated cell phenotype when compared to the control strain (Fig. 5A). However, overexpression of the $f k I B$ gene, in both the wild-type and mutant strains, BW25113(FkIB) and $\triangle F k I B(F k I B)$, resulted into a phenotype characterized by elongated cells that have stopped dividing (Fig. 5A, 6A).

Additionally, a mixed population of normal size cells and cells that were not dividing was noted in the swarmer cells of strains BW25113(FkIB) and $\triangle \mathrm{FkIB}(\mathrm{FkIB})$ overexpressing the fkIB gene (Fig. 5A, 6A). For these cells, we noticed an abnormality in the septa formation, that did not allow the separation of the cellular membrane for cell division.

Regarding the swimming motility, we noted that the phenotype of the mutant strain $\Delta \mathrm{FkIB}$ did not differ profoundly from the wild-type strain, BW25113. However, overexpression of the $f k I B$ gene in both strains, BW25113(FkIB) and $\triangle F k I B(F k I B)$, caused a pronounced cell elongation, in which it appeared that the cell division had been inhibited. Figure 5 shows that the cells of strain $\Delta F k I B(F k I B)$ formed multiple nucleoids, therefore we concluded that the replication of the genetic material was being done normally, while the cell wall and plasma membrane separation were not permitted (Fig. 5B, 6B).

The phenotype in both swarming and swimming cells seemed to reverse after the expression of the mutant gene, Y181A. Strains BW25113(Y181A) and $\triangle F k I B(Y 181 A)$ had a normal cell appearance under swarming and swimming conditions, that phenotypically corresponded to the wild-type strain. This observation led us to the conclusion that the cellular elongation of the strains BW25113(FklB) and $\triangle F k \mid B(F k I B)$ was due to the increased levels of the FkIB protein. Summing up the results, it was concluded that the accumulation of the FkIB protein, in the swarmer and swimmer cells, caused phenotype alterations that were specific to the increased PPlase activity (Fig. 5, 6). 


\section{Materials and Methods}

\section{E. coli strains, growth conditions and growth rate assay}

The bacterial strains and plasmids that were used in this study are described in Table 1. E. coli K-12 BW25113 and single-gene knockout mutants [39] were obtained from the E. coli Genetic Stock Center. Plasmid pCA24N, as well as plasmids pCA24N containing the PPlase encoding genes were obtained from the ASKA library of the NARA Institute [40]. Unless stated otherwise, bacteria were cultivated routinely in LB (Luria-Bertani) agar or broth at $37^{\circ} \mathrm{C}$ with aeration. When necessary, media were supplemented with chloramphenicol $(25 \mu \mathrm{g} / \mathrm{ml})$ or kanamycin $(25 \mu \mathrm{g} / \mathrm{ml})$ or ampicillin $(100 \mu \mathrm{g} / \mathrm{ml})$. The specific growth rates of the E. coli wild-type and mutant strains were determined by measuring the turbidity at $600 \mathrm{~nm}$ and C.F.U/ml for two independent cultures of each strain as a function of time with turbidity values less than 0.9.

\section{Plasmids}

The coding sequence of EcFkIB (NC_000913.3) was amplified using PCR and E. coli genomic DNA as a template. The primers used are Ec.b4207.H.F: 5'- CCAGGATCCGACCACCCCAACTTTTGACACC -3' and Ec.b3349.H.R: 5'- CGCAAGCTTTTAGAGGATTTCCAGCAGTTC -3'. The fragment excised from amplified EcFkIB sequence was cloned between BamHI and HindIII sites of pPROEX-HTa, resulting in pPROEX-HTa FkIB. Y181A point mutation in FkIB was engineered using the gene-SOE method described by Horton [41]. The mutagenic primers used are Ec.b4207.Y181A.F: 5'CCGCAGGAACTGGCAGCTGGCGAGCGCGGCGCA-3' and Ec.b4207.Y181A.R: 5'TGCGCCGCGCTCGCCATATGCCAGTTCCTGCGG-3'. The primary PCR products were purified and then used as templates for the second round of PCR. The final product was introduced into pPROEX-HTa, resulting in pPROEX-HTa Y181A. The nucleotide sequence of the gene encoding the mutant protein was confirmed by Sanger sequencing.

\section{Heterologous expression of FkIB in E. coli and purification of recombinant protein}

E. coli BL21(DE3)[ $\mathrm{F}^{-}$ompT gal dcm lon hsdS ${ }_{B}\left(r_{B}^{-} m_{B}^{-}\right) \lambda(D E 3$ [lacl lacUV5-T7 gene 1 ind1 sam7 nin5] (Novagen, Madison, WI, USA) was used as a host strain for overproduction of a His-tagged form of FkIB or Y181A. Synthesis of recombinant proteins in E. coli BL21 (DE3) cells was initiated by addition of 0.25 mM isopropyl 1-thio- $\beta$-D-galactopyranoside (IPTG) when the culture reached OD600 of 0.6 and continued cultivation for additional $4 \mathrm{~h}$ at $30^{\circ} \mathrm{C}$. Recombinant proteins were purified with Ni-NTA chromatography $\left(\mathrm{Ni}^{2+}\right.$-nitrilotriacetate, Qiagen) according to the manufacturer's instructions. To remove any imidazole and salts in the collected fractions, fractions were pooled accordingly and dialyzed against $35 \mathrm{mM}$ Hepes buffer $\mathrm{pH} 8.0$ and $70 \mathrm{mM} \mathrm{NaCl}$, for $12 \mathrm{~h}$. Production levels and purity of the recombinant proteins were analyzed by $15 \%$ SDS-PAGE electrophoresis. 


\section{Motility assays}

Overnight cultures of the different strains were grown, standardized to an OD600 of 1.2, and $3 \mu$ used to stab or spotted at the center of swimming and swarming plates, respectively. The swimming plates were prepared with $0.3 \%$ Fluka agar, 1\% Bacto-tryptone, $0.5 \%$ Yeast Extract and $1 \% \mathrm{NaCl}$. The swarming motility plates were prepared with $0.5 \%$ Fluka agar, $1 \%$ Bacto-tryptone, $0.5 \%$ Yeast Extract, $1 \% \mathrm{NaCl}$ and $0.5 \%$ glucose. When necessary, media were supplemented with chloramphenicol $(25 \mu \mathrm{g} / \mathrm{ml})$ or kanamycin $(25 \mu \mathrm{g} / \mathrm{ml})$ and the appropriate amounts of IPTG. The plates were dried for $1-2 \mathrm{~h}$ at room temperature before being inoculated and were scanned after $20 \mathrm{~h}$ incubation at $30^{\circ} \mathrm{C}$. Petri dishes were scanned and the swarming and swimming areas were measured with the imaging software ImageJ. The experiments were carried out in three replicates.

\section{Biofilm formation assay}

The crystal violet biofilm assays were performed as previously described [4]. Briefly, BW25113 and the fkIB mutant strains containing either pPROEX-HTa FkIB or pPROEX-HTa Y181A were grown overnight in LB medium. The overnight cultures were 1:10 diluted in $100 \mu \mathrm{l}$ of LB medium supplemented, when necessary, with appropriate concentrations of antibiotics and IPTG, and the biofilm was formed in covered $96-$ well microtiter dish for $20 \mathrm{~h}$ without shaking at $30^{\circ} \mathrm{C}$. The cell suspensions were removed and turbidity was measured at OD600. The plates were washed once with sterile distilled $\mathrm{H}_{2} \mathrm{O}$ to remove unbound bacteria and stained with $200 \mu \mathrm{l}$ crystal violet $(0.1 \%$ solution) for $20 \mathrm{~min}$. Quantification was conducted by suspending the crystal violet stained cells in $200 \mu \mathrm{l}$ of $20 \%$ acetone (in ethanol). Total biofilm formation was normalized by cell growth (turbidity at $600 \mathrm{~nm}$ ) to avoid overestimating changes due to growth effects. As controls, BW25113 fklB mutants with empty or pPROEX-HTa or pCA24N were used.

\section{Peptidyl-prolyl cis/trans isomerase enzymatic assay}

PPlase activity was tested using a chymotrypsin-coupled PPlase assay [19]. In this assay we measured the ability of FkIB or Y181A to convert the cis isomer of the synthetic oligopeptide substrate N-Suc-AlaLeu-Pro-Phe-p-nitroanilide into the trans form. The assay reaction contained $50 \mathrm{mM}$ Hepes buffer $\mathrm{pH} 8.0$ and $100 \mathrm{mM} \mathrm{NaCl}, 50 \mu \mathrm{g}$ a-chymotrypsin (dissolved in $1 \mathrm{mM} \mathrm{HCl}$ ) (Fluka), $25 \mu \mathrm{M}$ Suc-AAPF-pNA (5 mM stock dissolved in trifluoroethanol supplemented with $0.45 \mathrm{M} \mathrm{LiCl}$ ) and the appropriate amount of recombinant FkIB or $\mathrm{Y} 181 \mathrm{~A}$. The reaction was monitored at $4^{\circ} \mathrm{C}$ by the increase in absorbance at $390 \mathrm{~nm}$ (corresponding to the release of $p$-nitroanilide) using a HITACHI U-2800 spectrophotometer.

\section{Citrate synthase thermal aggregation assay}

Thermal denaturation of citrate synthase $(0.25 \mu \mathrm{M}$ final concentration, Sigma) was achieved by incubation at $45^{\circ} \mathrm{C}$, in $40 \mathrm{mM}$ Hepes $\mathrm{pH}: 7.5$, for $15-20 \mathrm{~min}$, in the absence or in the presence of additional proteins, 
as previously described [21]. Aggregation of citrate synthase was measured by monitoring the increase in turbidity at $500 \mathrm{~nm}$ in a HITACHI U-2800 spectrophotometer equipped with a thermostatic cell holder. The absorbance change recorded is due to the increase in light scattering upon aggregation of citrate synthase. Protein disulfide isomerase (Sigma) was used in positive control reactions and albumin (Research Organics) was used in negative control reactions. 


\section{References}

[1] N. Verstraeten et al., "Living on a surface: swarming and biofilm formation," Trends in Microbiology, vol. 16, no. 10, pp. 496-506, Oct. 2008.

[2] D. B. Kearns, "A field guide to bacterial swarming motility," Nat. Rev. Microbiol., vol. 8, no. 9, pp. 634644, Sep. 2010.

[3] G. L. Hazelbauer, J. J. Falke, and J. S. Parkinson, "Bacterial chemoreceptors: high-performance signaling in networked arrays," Trends Biochem. Sci., vol. 33, no. 1, pp. 9-19, Jan. 2008.

[4] G. A. O'Toole and R. Kolter, "Flagellar and twitching motility are necessary for Pseudomonas aeruginosa biofilm development," Mol. Microbiol., vol. 30, no. 2, pp. 295-304, Oct. 1998.

[5] M. E. Davey and G. A. O'toole, "Microbial biofilms: from ecology to molecular genetics," Microbiol. Mol. Biol. Rev., vol. 64, no. 4, pp. 847-867, Dec. 2000.

[6] S. W. Singer et al., "Posttranslational modification and sequence variation of redox-active proteins correlate with biofilm life cycle in natural microbial communities," ISME J, vol. 4, no. 11, pp. 13981409, Nov. 2010.

[7] Z. Li et al., "Diverse and divergent protein post-translational modifications in two growth stages of a natural microbial community," Nat Commun, vol. 5, p. 4405, Jul. 2014.

[8] S. L. Rutherford and C. S. Zuker, "Protein folding and the regulation of signaling pathways," Cell, vol. 79, no. 7, pp. 1129-1132, Dec. 1994.

[9] C. B. Kang, Y. Hong, S. Dhe-Paganon, and H. S. Yoon, "FKBP family proteins: immunophilins with versatile biological functions," Neurosignals, vol. 16, no. 4, pp. 318-325, 2008.

[10]P. Vittorioso, R. Cowling, J. D. Faure, M. Caboche, and C. Bellini, "Mutation in the Arabidopsis PASTICCINO1 gene, which encodes a new FK506-binding protein-like protein, has a dramatic effect on plant development," Mol. Cell. Biol., vol. 18, no. 5, pp. 3034-3043, May 1998.

[11]A. Breiman and I. Camus, "The involvement of mammalian and plant FK506-binding proteins (FKBPs) in development," Transgenic Res., vol. 11, no. 4, pp. 321-335, Aug. 2002.

[12]M. Geisler and A. Bailly, "Tête-à-tête: the function of FKBPs in plant development," Trends Plant Sci., vol. 12, no. 10, pp. 465-473, Oct. 2007.

[13]M. Gaestel, "Molecular chaperones in signal transduction," Handb Exp Pharmacol, no. 172, pp. 93109, 2006.

[14]J. U. Rahfeld et al., "Isolation and amino acid sequence of a new 22-kDa FKBP-like peptidyl-prolyl cis/trans-isomerase of Escherichia coli. Similarity to Mip-like proteins of pathogenic bacteria," J. Biol. Chem., vol. 271, no. 36, pp. 22130-22138, Sep. 1996.

[15]N. Zang et al., "Requirement of a mip-like gene for virulence in the phytopathogenic bacterium Xanthomonas campestris pv. campestris," Mol. Plant Microbe Interact., vol. 20, no. 1, pp. 21-30, Jan. 2007.

[16]C. Budiman, K. Bando, C. Angkawidjaja, Y. Koga, K. Takano, and S. Kanaya, "Engineering of monomeric FK506-binding protein 22 with peptidyl prolyl cis-trans isomerase. Importance of a Vshaped dimeric structure for binding to protein substrate," FEBS J., vol. 276, no. 15, pp. 4091-4101, Aug. 2009.

[17]B. Jana, A. Bandhu, R. Mondal, A. Biswas, K. Sau, and S. Sau, "Domain structure and denaturation of a dimeric Mip-like peptidyl-prolyl cis-trans isomerase from Escherichia coli," Biochemistry, vol. 51, no. 6, pp. 1223-1237, Feb. 2012.

[18]C. Budiman, C. Angkawidjaja, H. Motoike, Y. Koga, K. Takano, and S. Kanaya, "Crystal structure of N-domain of FKBP22 from Shewanella sp. SIB1: dimer dissociation by disruption of Val-Leu knot," Protein Sci., vol. 20, no. 10, pp. 1755-1764, Oct. 2011.

[19]J. L. Kofron, P. Kuzmic, V. Kishore, E. Colón-Bonilla, and D. H. Rich, "Determination of kinetic constants for peptidyl prolyl cis-trans isomerases by an improved spectrophotometric assay," Biochemistry, vol. 30, no. 25, pp. 6127-6134, Jun. 1991.

[20]C. Budiman, T. Tadokoro, C. Angkawidjaja, Y. Koga, and S. Kanaya, "Role of polar and nonpolar residues at the active site for PPlase activity of FKBP22 from Shewanella sp. SIB1," FEBS J., vol. 279, no. 6, pp. 976-986, Mar. 2012.

[21]J. Buchner, H. Grallert, and U. Jakob, "Analysis of chaperone function using citrate synthase as nonnative substrate protein," Meth. Enzymol., vol. 290, pp. 323-338, 1998. 
[22]R. P. Jakob, G. Zoldák, T. Aumüller, and F. X. Schmid, "Chaperone domains convert prolyl isomerases into generic catalysts of protein folding," Proc. Natl. Acad. Sci. U.S.A., vol. 106, no. 48, pp. 2028220287, Dec. 2009.

[23]G. Zoldák and F. X. Schmid, "Cooperation of the prolyl isomerase and chaperone activities of the protein folding catalyst SlyD," J. Mol. Biol., vol. 406, no. 1, pp. 176-194, Feb. 2011.

[24]A. Galat, "Peptidylprolyl cis/trans isomerases (immunophilins): biological diversity--targets--functions," Curr Top Med Chem, vol. 3, no. 12, pp. 1315-1347, 2003.

[25]T. Inoue, R. Shingaki, S. Hirose, K. Waki, H. Mori, and K. Fukui, "Genome-wide screening of genes required for swarming motility in Escherichia coli K-12,” J. Bacteriol., vol. 189, no. 3, pp. 950-957, Feb. 2007.

[26]A. Skagia, C. Zografou, E. Vezyri, A. Venieraki, P. Katinakis, and M. Dimou, "Cyclophilin PpiB is involved in motility and biofilm formation via its functional association with certain proteins," Genes Cells, vol. 21, no. 8, pp. 833-851, Aug. 2016.

[27]A. Skagia et al., "Structural and functional analysis of cyclophilin PpiB mutants supports an in vivo function not limited to prolyl isomerization activity," Genes Cells, vol. 22, no. 1, pp. 32-44, Jan. 2017.

[28]M. M. Pearson, D. A. Rasko, S. N. Smith, and H. L. T. Mobley, "Transcriptome of swarming Proteus mirabilis," Infect. Immun., vol. 78, no. 6, pp. 2834-2845, Jun. 2010.

[29]M. J. McBride and T. F. Braun, "Gldl is a lipoprotein that is required for Flavobacterium johnsoniae gliding motility and chitin utilization," J. Bacteriol., vol. 186, no. 8, pp. 2295-2302, Apr. 2004.

[30]M. Klausen et al., "Biofilm formation by Pseudomonas aeruginosa wild type, flagella and type IV pili mutants," Mol. Microbiol., vol. 48, no. 6, pp. 1511-1524, Jun. 2003.

[31]N. C. Caiazza, R. M. Q. Shanks, and G. A. O'Toole, "Rhamnolipids modulate swarming motility patterns of Pseudomonas aeruginosa," J. Bacteriol., vol. 187, no. 21, pp. 7351-7361, Nov. 2005.

[32]A. Skagia et al., "Structure-Function Analysis of the Periplasmic Escherichia coli Cyclophilin PpiA in Relation to Biofilm Formation," J. Mol. Microbiol. Biotechnol., vol. 27, no. 4, pp. 228-236, 2017.

[33]F. Fujimori et al., "Crosstalk of prolyl isomerases, Pin1/Ess1, and cyclophilin A," Biochem. Biophys. Res. Commun., vol. 289, no. 1, pp. 181-190, Nov. 2001.

[34]Y. Mamane, S. Sharma, L. Petropoulos, R. Lin, and J. Hiscott, "Posttranslational regulation of IRF-4 activity by the immunophilin FKBP52," Immunity, vol. 12, no. 2, pp. 129-140, Feb. 2000.

[35]C. Allison and C. Hughes, "Bacterial swarming: an example of prokaryotic differentiation and multicellular behaviour," Sci Prog, vol. 75, no. 298 Pt 3-4, pp. 403-422, 1991.

[36]R. M. Harshey, "Bees aren't the only ones: swarming in gram-negative bacteria," Mol. Microbiol., vol. 13, no. 3, pp. 389-394, Aug. 1994.

[37]L. McCarter and M. Silverman, "Surface-induced swarmer cell differentiation of Vibrio parahaemolyticus," Mol. Microbiol., vol. 4, no. 7, pp. 1057-1062, Jul. 1990.

[38]A. Skagia, C. Zografou, A. Venieraki, C. Fasseas, P. Katinakis, and M. Dimou, "Functional analysis of the cyclophilin PpiB role in bacterial cell division," Genes Cells, vol. 22, no. 9, pp. 810-824, Sep. 2017.

[39]T. Baba et al., "Construction of Escherichia coli K-12 in-frame, single-gene knockout mutants: the Keio collection," Mol. Syst. Biol., vol. 2, p. 2006.0008, 2006.

[40]M. Kitagawa et al., "Complete set of ORF clones of Escherichia coli ASKA library (a complete set of E. coli K-12 ORF archive): unique resources for biological research," DNA Res., vol. 12, no. 5, pp. 291299, 2005.

[41]R. M. Horton, H. D. Hunt, S. N. Ho, J. K. Pullen, and L. R. Pease, "Engineering hybrid genes without the use of restriction enzymes: gene splicing by overlap extension," Gene, vol. 77, no. 1, pp. 61-68, Apr. 1989. 


\section{Figures and figure legends}
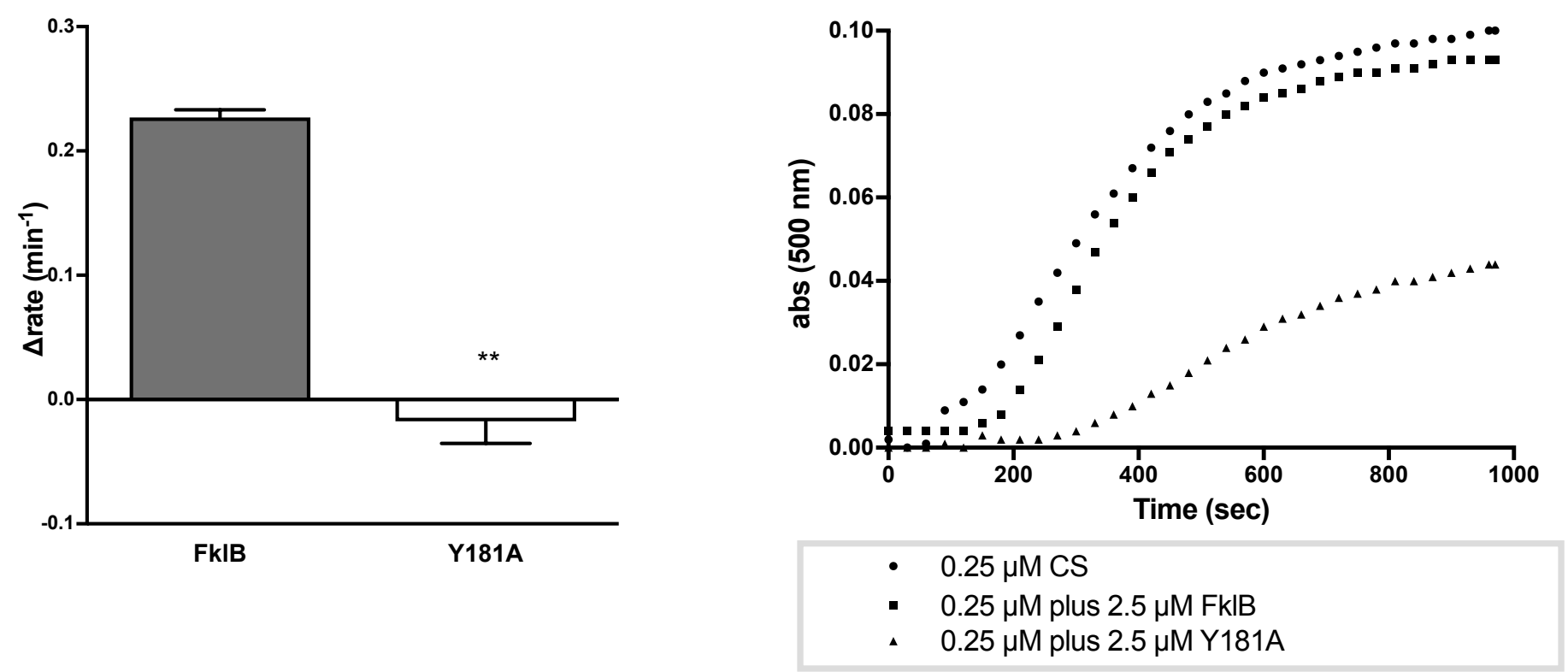

Figure 1. Prolyl isomerase and chaperone activity is lost in mutant $\mathrm{Y} 181 \mathrm{~A}$ compared to the wild-type protein FkIB.

A. PPlase activity of $0.25 \mathrm{uM} \mathrm{FkIB}$ and Y181A. Mean values were obtained from three independent replicates and error bars represent standard errors.
B. Thermal aggregation of citrate synthase in the absence $(\bullet)$ and presence of $(\boldsymbol{\square}) 0.25 \mathrm{uM} \mathrm{FkIB}$ or $0.25 \mathrm{uM} \mathrm{Y181A}(\mathbf{\Delta})$. The results are representative of three series of measurements carried out with different preparations of enzymes. 
A

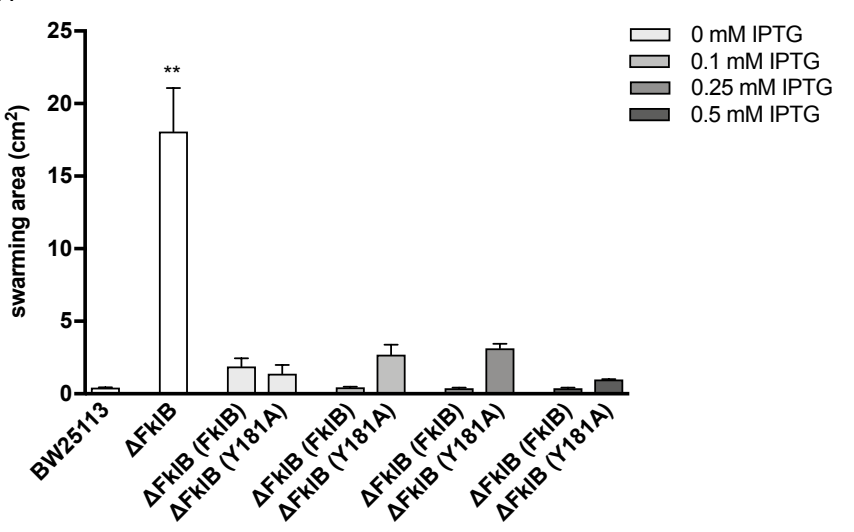

C

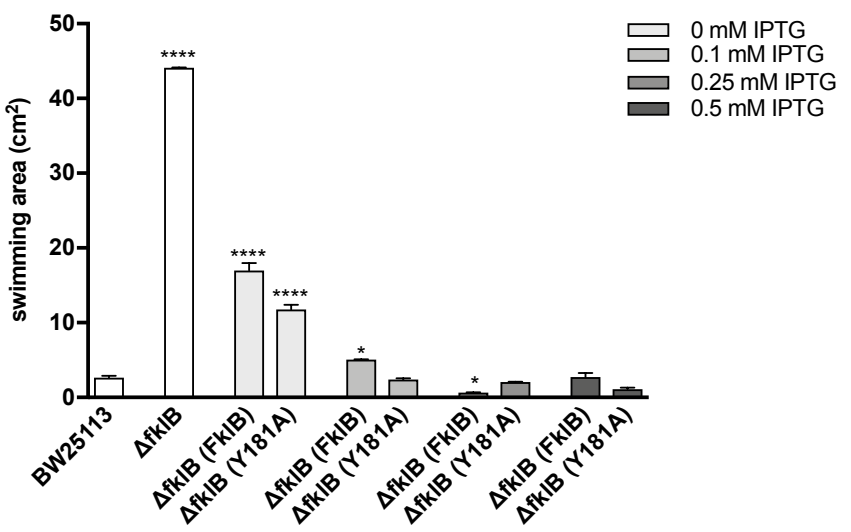

B
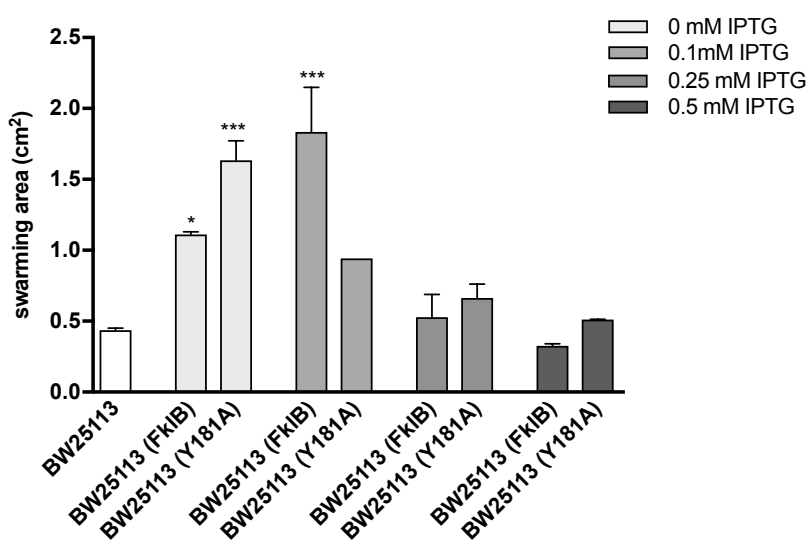

D

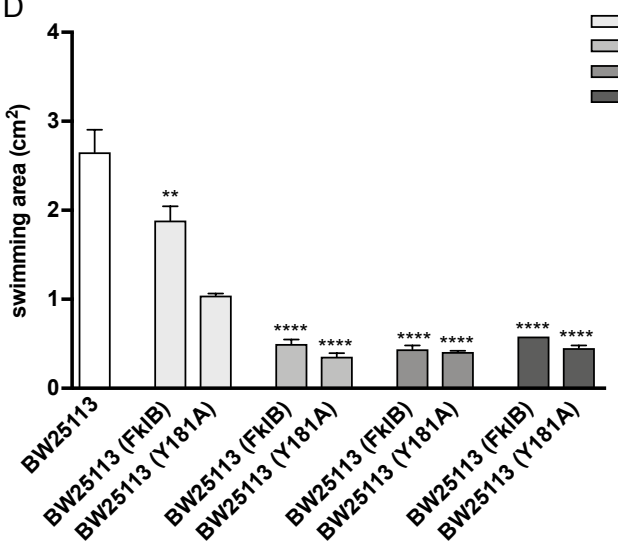

Figure 2. Prolyl isomerase activity of FkIB causes a suppression of the swarming and swimming phenotype in $E$. coli. Swarming (A) and swimming $(C)$ area of the $\triangle$ FkIB mutant strain that overexpresses FkIB and $Y 181 \mathrm{~A}$ and swarming (B) and swimming area (D) of BW25113 that overexpresses FkIB and Y181A, compared to the wild-type BW25113. Mean values were obtained from four independent replicates, and error bars represent standard errors. Statistical comparisons were made using ANOVA followed by Dunnett's multiple-comparison test. Asterisks indicate statistically significant differences $(P<0.05)$. 

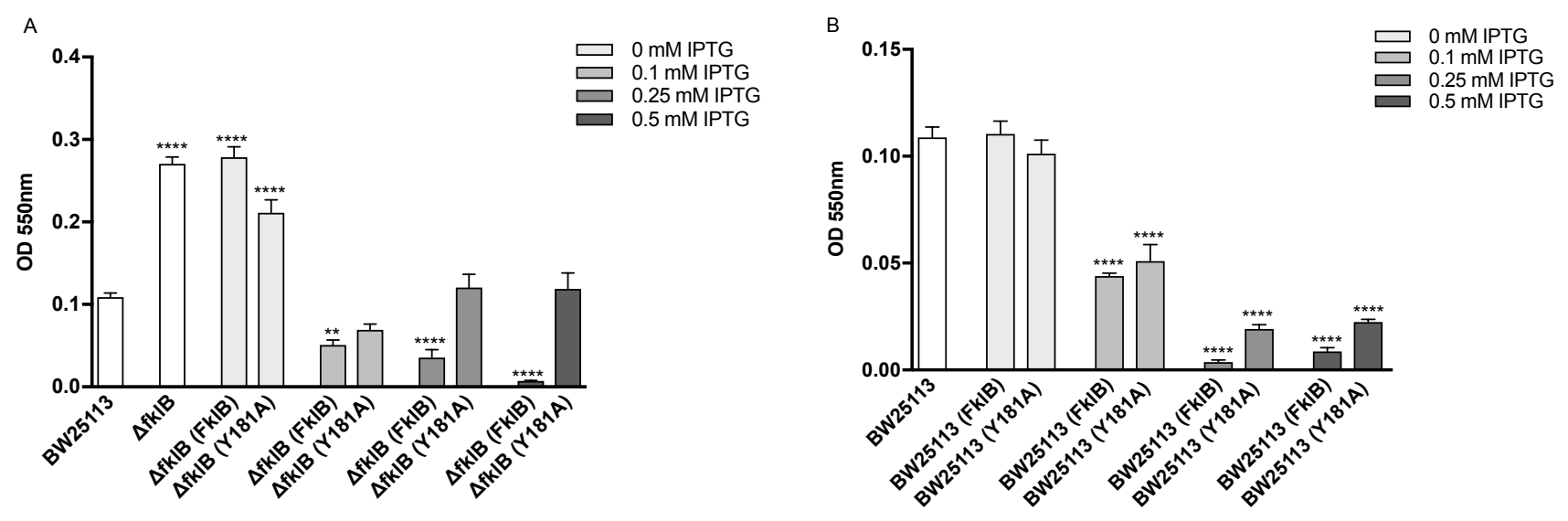

Figure 3. Prolyl isomerase activity of FkIB causes a suppression of the biofilm phenotype in E. coli. Biofilm formation of the $\triangle$ FkIB mutant strain that overexpresses FkIB and Y181A (A) and of the BW25113 that overexpresses FkIB and Y181A (B), compared to the wild-type BW25113. Mean values were obtained from four independent replicates, and error bars represent standard errors. Statistical comparisons were made using ANOVA followed by Dunnett's multiple-comparison test. Asterisks indicate statistically significant differences $(P<0.05)$. 


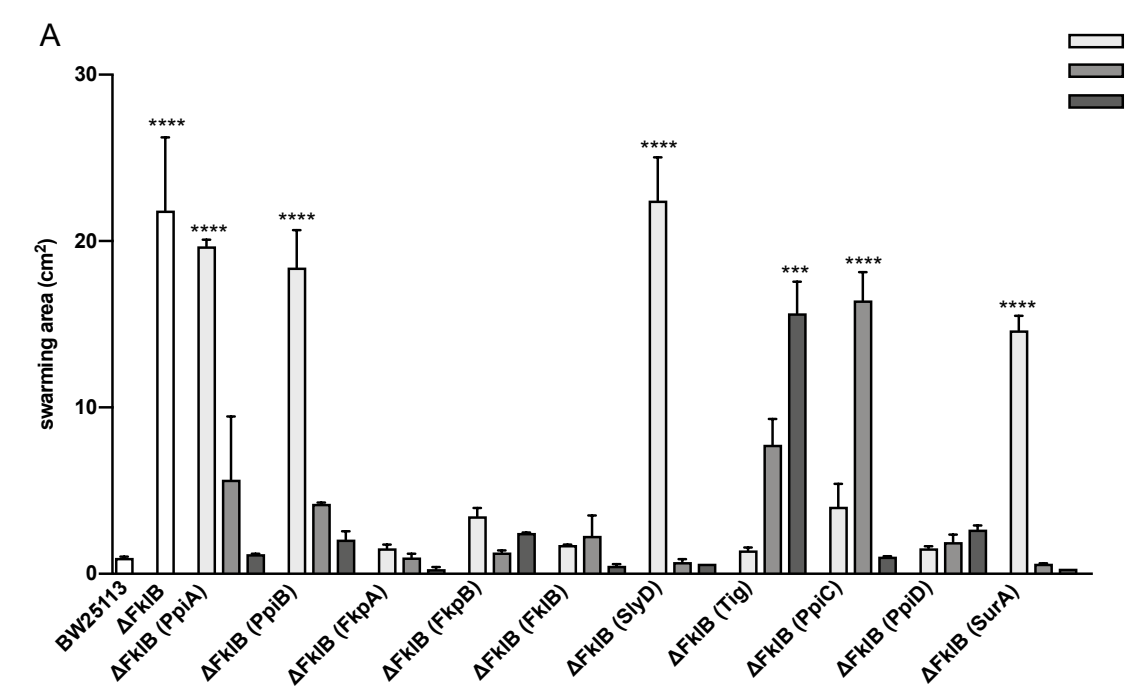

B
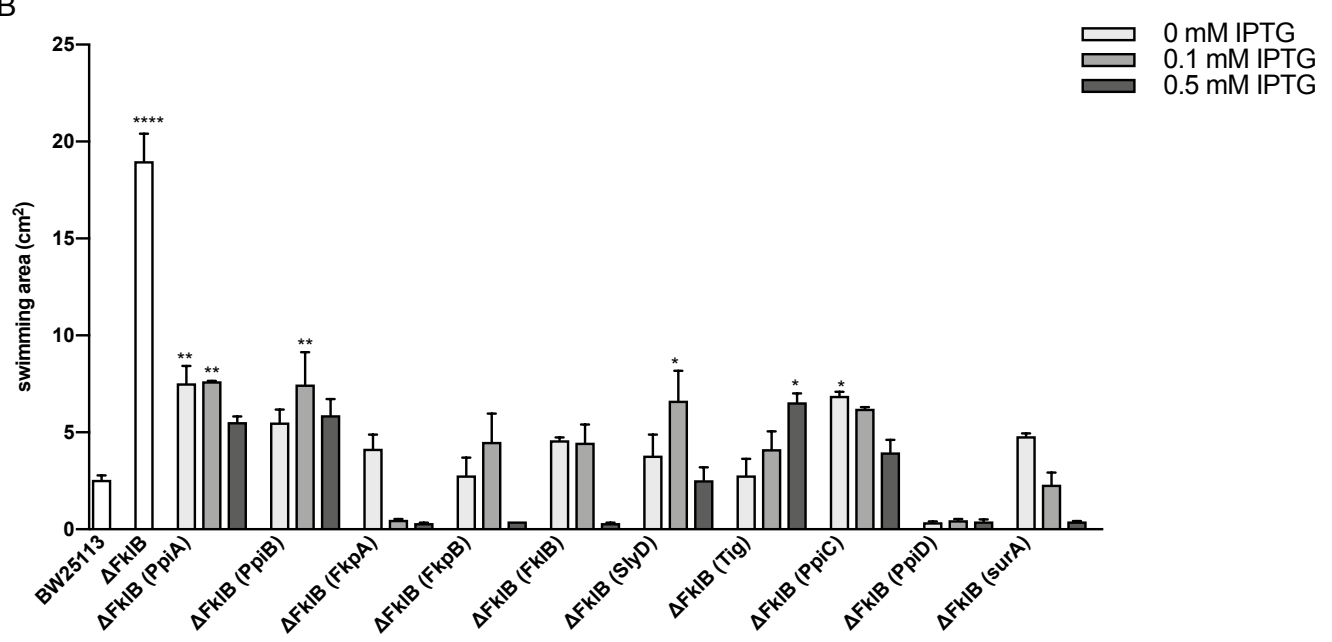

C
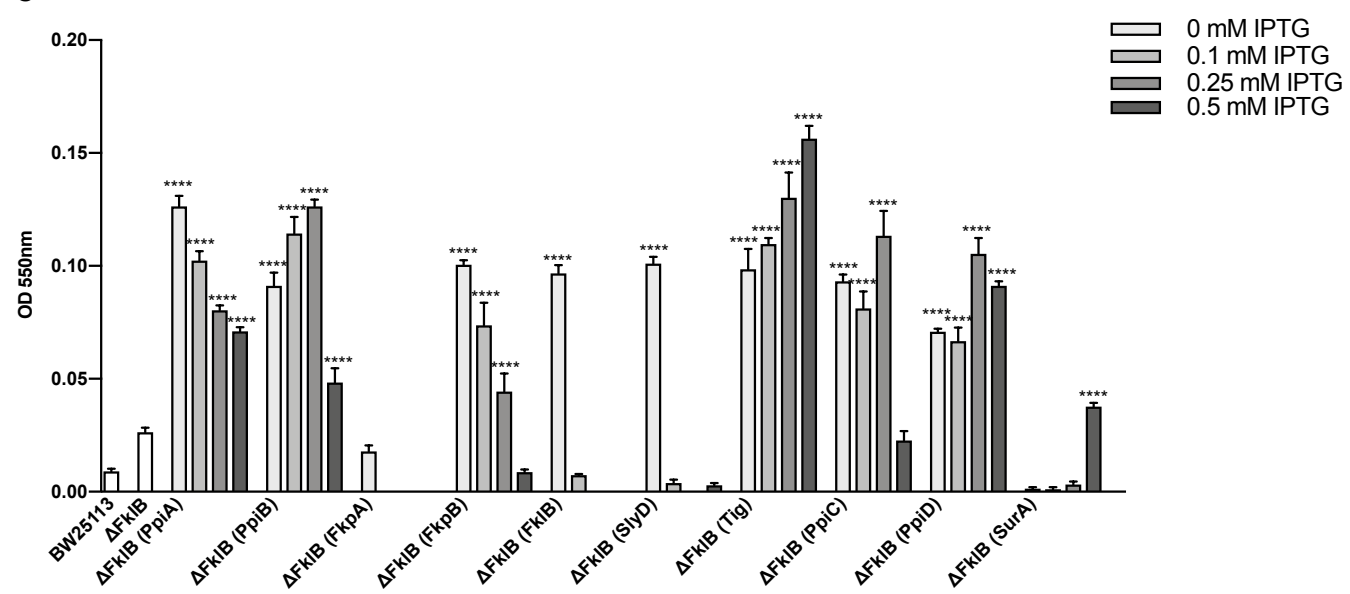

Figure 4. Members of the prolyl isomerase family restore the FkIB mutant strain phenotypes. Swarming area (A), swimming area (B), and biofilm formation (C) of $\triangle \mathrm{FkIB}$ and $\triangle \mathrm{FkIB}$ overexpressing each PPlase family member, PpiA, PpiB, PpiC, FkpA, FkpB, FklB, SlyD, Tig, PpiC, PpiD, SurA in pCA24N vector. 
bioRxiv preprint doi: https://doi.org/10.1101/2020.02.01.930347; this version posted February 2, 2020. The copyright holder for this preprint (which was not certified by peer review) is the author/funder, who has granted bioRxiv a license to display the preprint in perpetuity. It is made available under aCC-BY-ND 4.0 International license.

A

Swarming cells

Control BW25113

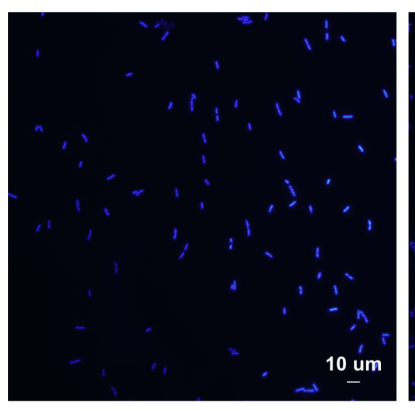

$\Delta \mathrm{FklB}$
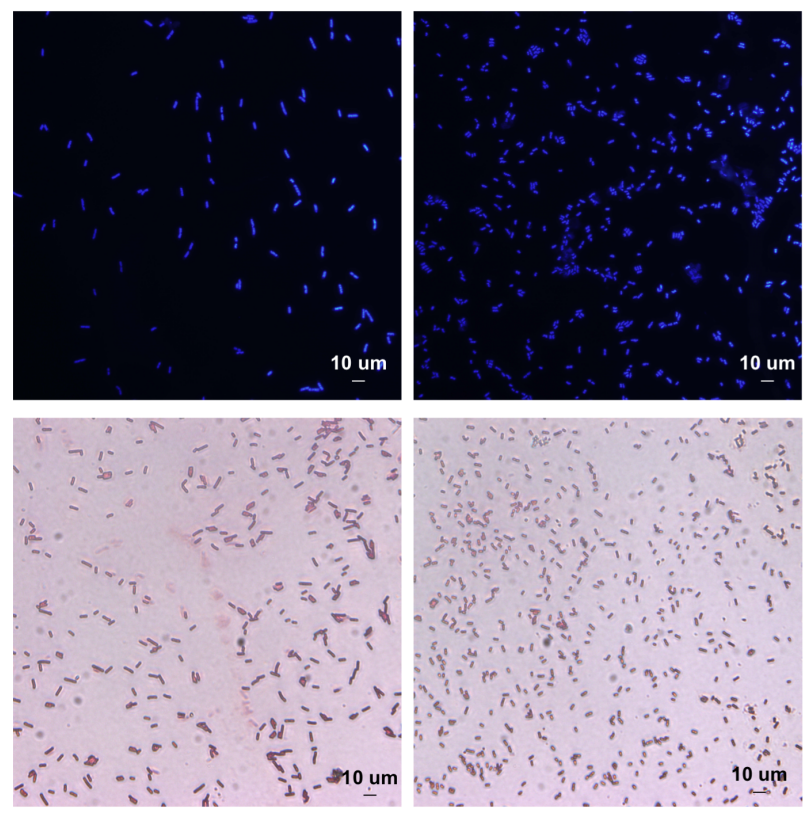

B Swimming cells

Control BW25113

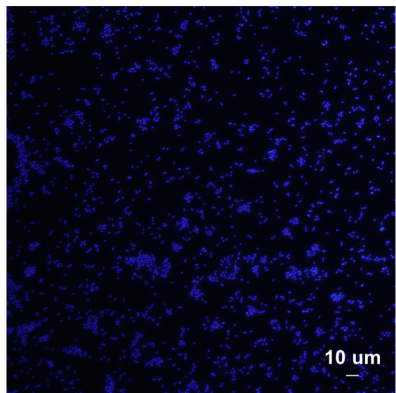

$\triangle \mathrm{FkIB}$
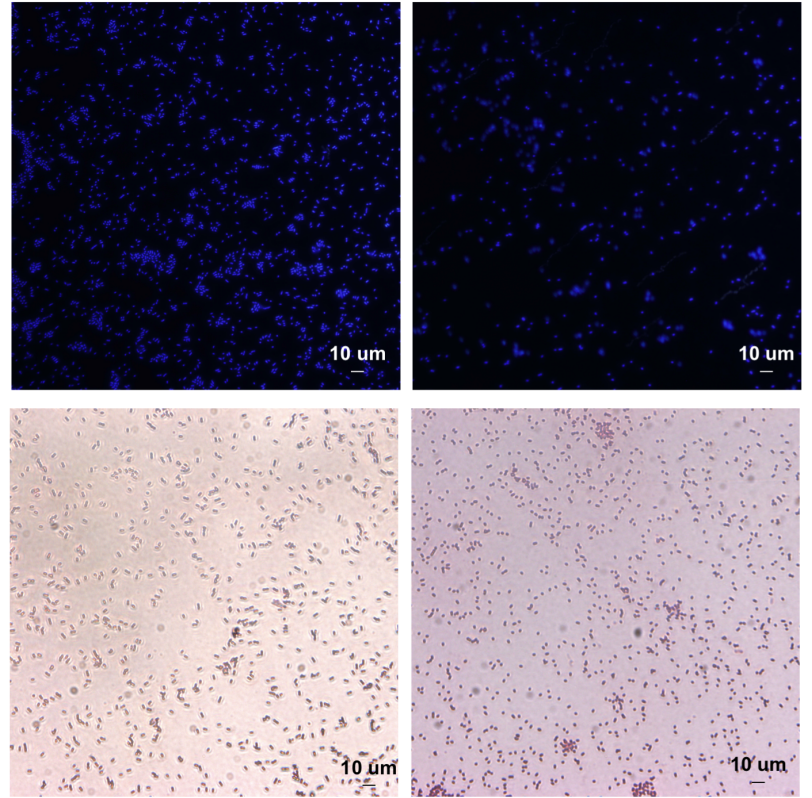

$\Delta \mathrm{FkIB}(\mathrm{FkIB})$
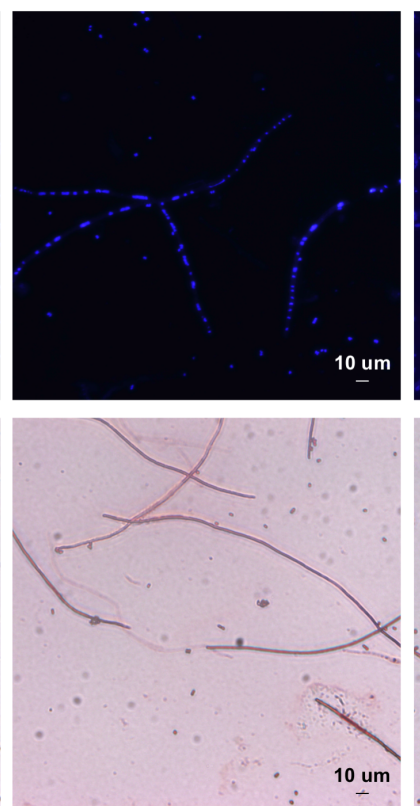

$\Delta \mathrm{FkIB}(\mathrm{Y} 181 \mathrm{~A})$
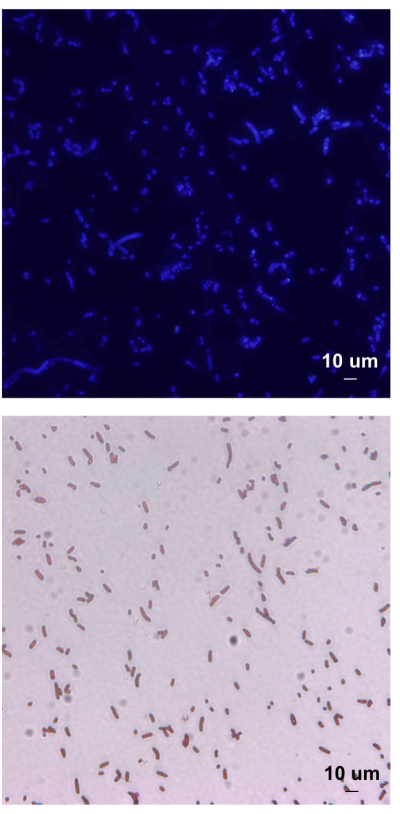

$\Delta \mathrm{FklB}(\mathrm{FklB})$
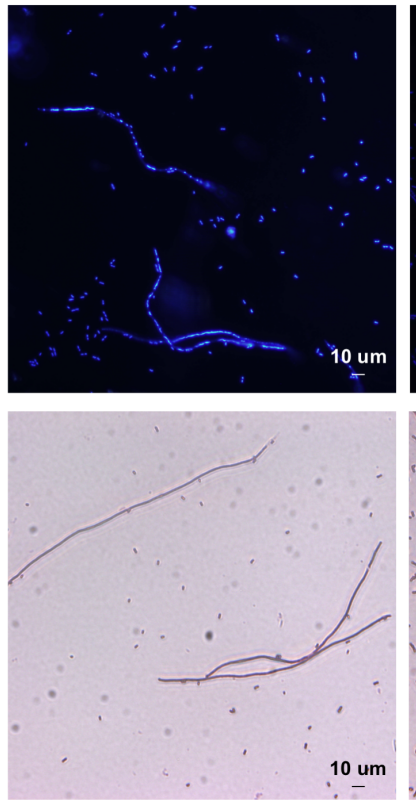

$\triangle \mathrm{FkIB}(\mathrm{Y} 181 \mathrm{~A})$
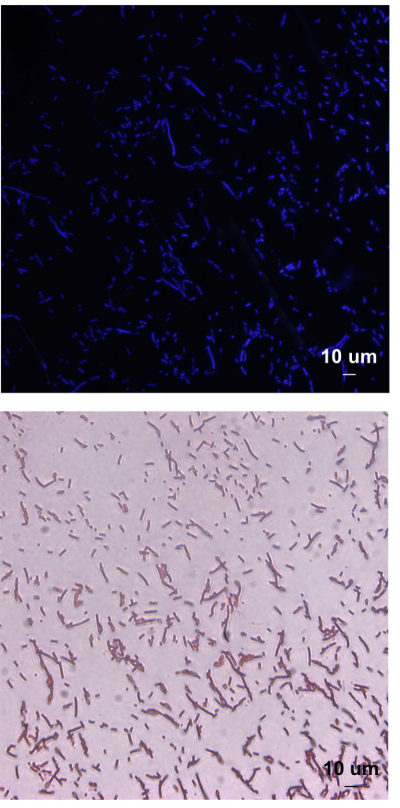

Figure 5. Overexpression of FkIB, but not $\mathrm{Y} 181 \mathrm{~A}$, in $\triangle \mathrm{FklB}$ causes a cell elongation phenotype in swarming and swimming E. coli. $\triangle$ FkIB and $\triangle$ FkIB overexpressing FkIB or Y181A in pCA24N vector taken from swarming (A) and swimming (B) cells were examined after DAPI (upper row) or Gram (bottom row) staining by light and fluorescent microscopy and compared to the control, BW25113. Bars represent 10 um. 
bioRxiv preprint doi: https://doi.org/10.1101/2020.02.01.930347; this version posted February 2, 2020. The copyright holder for this preprint (which was not certified by peer review) is the author/funder, who has granted bioRxiv a license to display the preprint in perpetuity. It is made available under aCC-BY-ND 4.0 International license.

A Swarming cells

Control BW25113
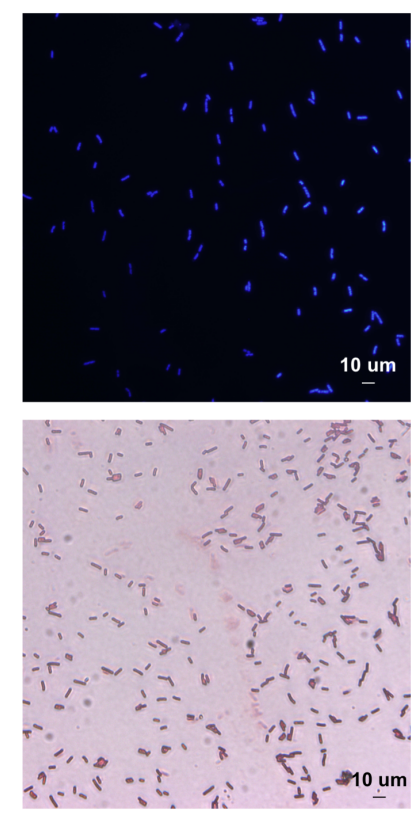

B Swimming cells

Control BW25113
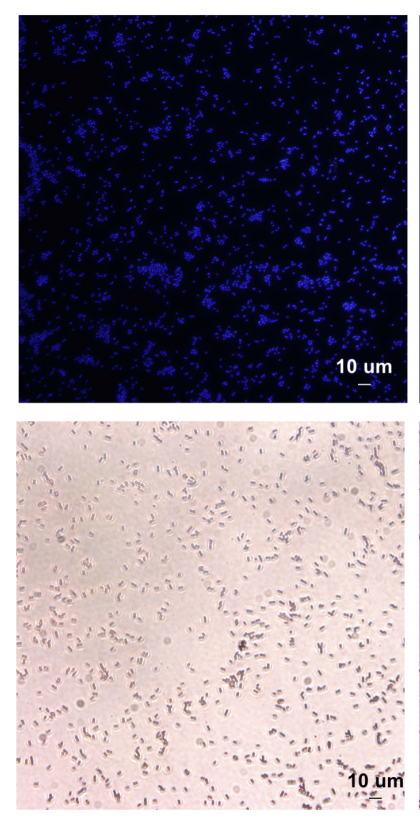

BW25113 (FkIB)
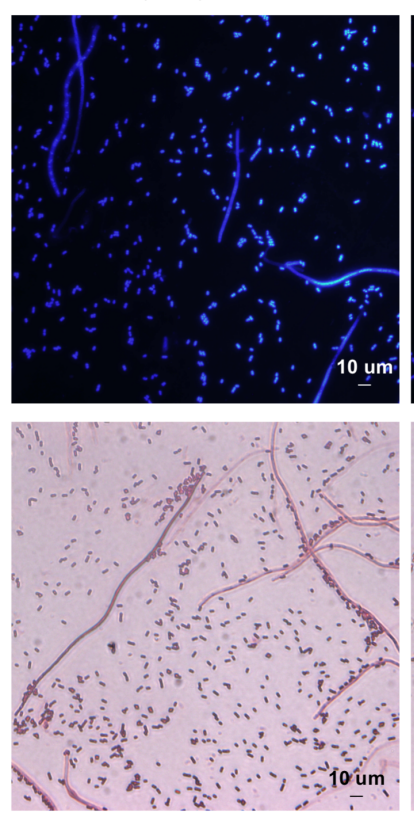

BW25113 (FkIB)
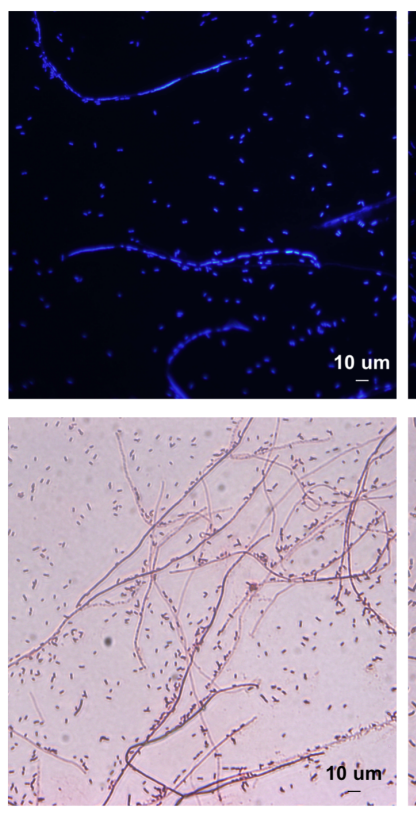

BW25113 (Y181A)
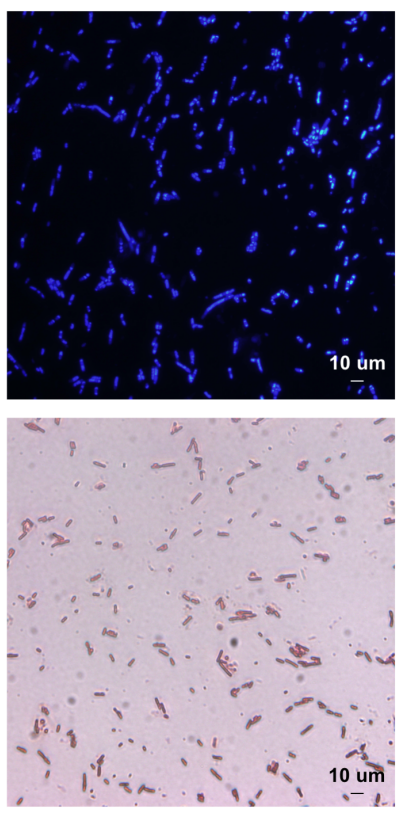

BW25113 (Y181A)
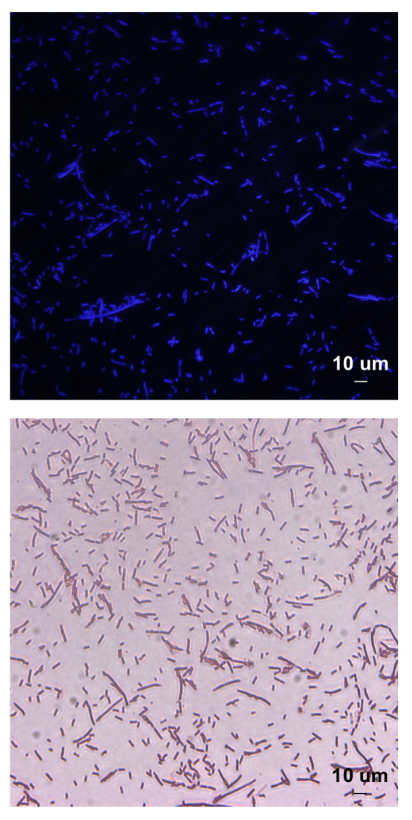

Figure 6. Overexpression of FkIB, but not $\mathrm{Y} 181 \mathrm{~A}$, in BW25113 causes a cell elongation phenotype in swarming and swimming E. coli. BW25113 overexpressing FkIB or Y181A in pCA24N vector taken from swarming (A) and swimming (B) cells were examined after DAPI (upper row) or Gram (bottom row) staining by light and fluorescent microscopy and compared to the control, BW25113. Bars represent $10 \mathrm{um}$. 